Review Article

\title{
The Role of the Transcription Factor Foxo3 in Hearing Maintenance: Informed Speculation on a New Player in the Cochlea
}

\author{
Patricia M. White \\ Department of Neuroscience, University of Rochester School of Medicine and Dentistry, Box 603, 601 Elmwood Avenue, \\ Rochester, NY 14642, USA
}

Correspondence should be addressed to Patricia M. White; patricia_white@urmc.rochester.edu

Received 31 May 2016; Revised 31 August 2016; Accepted 19 September 2016

Academic Editor: Kenneth W. Altman

Copyright (C) 2016 Patricia M. White. This is an open access article distributed under the Creative Commons Attribution License, which permits unrestricted use, distribution, and reproduction in any medium, provided the original work is properly cited.

Molecular genetics has proven to be a powerful approach for understanding early-onset hearing loss. Recent work in late-onset hearing loss uses mouse genetics to identify molecular mechanisms that promote the maintenance of hearing. One such gene, Foxo3, is ontologically involved in preserving mitochondrial function. Significant evidence exists to support the idea that mitochondrial dysfunction is correlated with and can be causal for hearing loss. Foxo3 is also ontologically implicated in driving the circadian cycle, which has recently been shown to influence the molecular response to noise damage. In this review, the molecular framework connecting these cellular processes is discussed in relation to the cellular pathologies observed in human specimens of late-onset hearing loss. In bringing these observations together, the possibility arises that distinct molecular mechanisms work in multiple cell types to preserve hearing. This diversity offers great opportunities to understand and manipulate genetic processes for therapeutic gain.

\section{Introduction}

One in eight adults has hearing loss, and the likelihood of hearing loss increases as one's age advances [1]. Environmental insults that damage hearing are well known. For example, hearing loss may develop after exposure to prolonged and excessive noise [2] or to ototoxic drugs such as aminoglycosides [3]. Each individual likely has genetic variation in their susceptibility to these insults [4]. Over a hundred genes that affect hearing loss during development have been identified [5]. In contrast, five genome-wide association studies in humans have implicated only a handful of genes in agerelated hearing loss $[4,6-9]$.

Sensory cells of the mammalian cochlea continuously detect and transmit acoustic information throughout the life of the animal. Outer hair cells amplify acoustic vibrations of the tectorial membrane to promote inner hair cell activation. Inner hair cells detect these vibrations and transmit the information to spiral ganglion neurons via ribbon synapses. Sensory hair cell signaling is powered by differential levels of potassium in separate fluid compartments, called the endocochlear potential. The endocochlear potential is actively maintained by the cells of the stria vascularis, in combination with supporting cells and the cells of the spiral ligament. No regeneration has been reported for lost cells in the adult organ of Corti. Consequently, any cellular losses will persist and accumulate through the lifetime of the mammal.

Animal models have elucidated the cellular pathological sequelae of specific inner ear insults [10]. Noise exposure, particularly loud, low-frequency sounds, can destroy outer hair cells in the basal turn [11], termed noise-induced hearing loss. Noise exposure that induces temporary changes in hearing can simultaneously eliminate high-frequency ribbon synapses [12, 13]. Termed synaptopathy, synaptic losses, can occur even when hair cells are completely preserved [12-14]. Glutamate toxicity is one probable mechanism for synaptic loss after noise exposure [15]. Neuronal loss can follow synaptic loss [12]. Administration of aminoglycoside antibiotics also results in hair cell death and spiral neuron degeneration in humans [16, 17] and other species [18]. In addition, injury 
to the stria vascularis can degrade hearing ability. Reduced endocochlear potential and concomitant hearing loss have been reported in aged gerbils [19]. Moreover, application of furosemide, a diuretic and inhibitor of the $\mathrm{Na}-\mathrm{K}-2 \mathrm{Cl}$ symporter (NKCC2), to the gerbil inner ear both reduces endocochlear potential and induces hearing loss [20,21].

Given that a limited number of cell types participate in hearing and the fact that ototoxic insults preferentially affect specific structures in animals, one could imagine designing a suite of therapeutics that each addresses individual kinds of damage. For example, one drug could be designed that protects synapses from glutamate toxicity. Another one could restore the endocochlear potential, and a third one could protect or regenerate outer hair cells. For this thought experiment, it is important to consider the cellular pathologies commonly found in human disease.

Qualitative analysis of human postmortem samples reveals cellular pathology similar to animal models. Loss of outer hair cells, especially in the basal turn, is a common finding [14], along with strial atrophy [22]. Individuals over 50 years of age have on average 30\% fewer spiral ganglion neurons, with losses more evident in the basal region $[23,24]$. Total spiral ganglion losses increase to $50 \%$ for individuals over 80 [23]. Loss of dendritic afferents is observed in human postmortem samples, consistent with synaptic losses [14, 25]. Nonetheless, spiral ganglion neurons can still persist for decades after the onset of hearing loss, as they are frequently detected in postmortem samples from such patients [26].

Surprisingly, quantitative studies have found that human hearing metrics correlate poorly with anticipated cellular pathology. For example, while one might predict that reduced strial function should affect hearing at all frequencies, quantitative studies demonstrate that reduced strial volumes correlate strongly with high-frequency hearing loss and not with general hearing impairment [22, 27]. Similarly, a survey of older patients with high-frequency hearing loss shows that many patients retain outer hair cell activity, measured by the production of otoacoustic emissions [28]. These findings suggest that a mix of endocochlear and sensory hair cell dysfunctions may be a common mechanism in high-frequency hearing loss without specific environmental injury. Indeed, in the majority of postmortem specimens from humans with hearing loss, a combination of stria vascularis degeneration, hair cell loss, and neuronal loss is observed [22, 27, 29]. Similar findings are reported in aged non-human primates [30]. Principle component analysis of large datasets suggests that, in general, human cellular pathology in hearing loss does not naturally segregate into categories with unique cellular losses [31].

Taken together, these findings draw attention to a basic scientific question: which genes promote the survival and function of the various cells in the cochlea? Do different alleles for these genes govern a propensity to hearing loss, which varies among people? Do different genetic pathways protect different structures? If so, why are combinations of cellular damage common in older individuals with hearing loss? An interlocking network of genes regulates cellular responses to oxidative stress, metabolism, and circadian rhythm. Some genes in this network are implicated in hearing loss. However, there has not been a systematic approach to matching genetic pathways to the structures that they may protect. Once specific protective gene networks are identified, network members could become targets for therapeutics for treating hearing loss.

I propose the transcription factor Foxo3 as a candidate member for such a network that protects hearing under stress. Foxo3 is expressed in adult mouse cochlear sensory hair cells and spiral ganglion neurons [32]. In other systems, Foxo3 regulates a number of molecular pathways that promote survival and preserve function in long-lived cells. In this review, I will first provide an overview of Foxo3, its role in human longevity, and its regulation. I will describe Foxo3's role in the mouse cochlea. I will discuss recent findings that strongly implicate a role for mitochondrial function in hearing maintenance [33] in the context of Foxo3 target genes that regulate mitochondrial biogenesis and function [34]. Lastly, I will cover recent findings on how the circadian cycle affects hearing recovery after damage, in the context of Foxo3's regulation of circadian cycle [35]. Taken together, these findings indicate that cellular metabolism strongly influences the preservation of hearing, and investigations into the regulation of cochlear cellular metabolism may refine our understanding of hearing loss.

\section{Introducing Foxo3 and Its Effects on Hearing}

Foxo3 is a transcription factor of the winged helix class. It was first identified as a longevity gene in the model system Caenorhabditis elegans [36] and is now known as part of a metabolic network that regulates lifespan in many organisms [37]. Specific human variant alleles of Foxo3 have been linked to extreme longevity in multiple populations [38-43]. These alleles increase the amount of Foxo3 expressed in tissues [44], suggesting a protective effect.

Foxo3 nuclear localization and transcriptional activity are regulated by a variety of extrinsic signals (Figure 1(a)). When cellular metabolic activity is low or blood sugar is high, the insulin receptor effector Akt phosphorylates Foxo3, sequestering it in the cytoplasm and blocking its activity [4547]. When cellular metabolic activity increases, for example, during energy stress or after intense firing in neural cells, ATP levels drop and cAMP levels climb. This activates the cAMP-dependent kinase Ampk, which promotes Foxo3 transcriptional activity in two ways [48]. Transient Ampk activation inhibits Akt, allowing Foxo3 activation and nuclear localization. Under prolonged Ampk activation, Ampk localizes to the nucleus and phosphorylates Foxo3, to alter its DNA sequence binding specificity and to drive transcription of targets that promote stress resistance [49, 50]. Stressactivated Jnk, an immediate-early response kinase, can also target Foxo3 with site-specific phosphorylation that alters its binding affinity [51]. Besides phosphorylation, Foxo3 is also regulated through acetylation on lysine residues. To bind to DNA, Foxo3 requires the action of $\mathrm{Cbp}$, nuclear acetylase that can open DNA for transcription through histone 


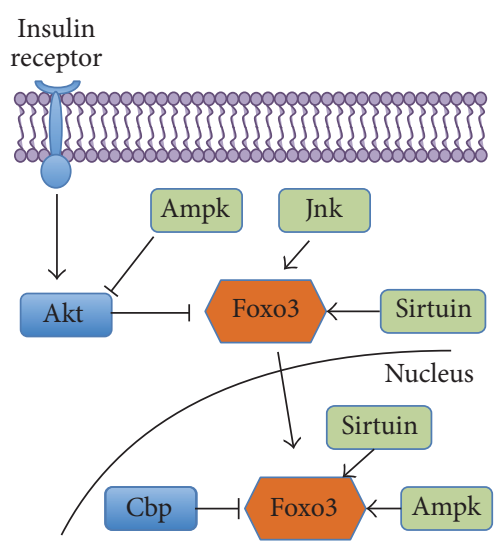

(a)

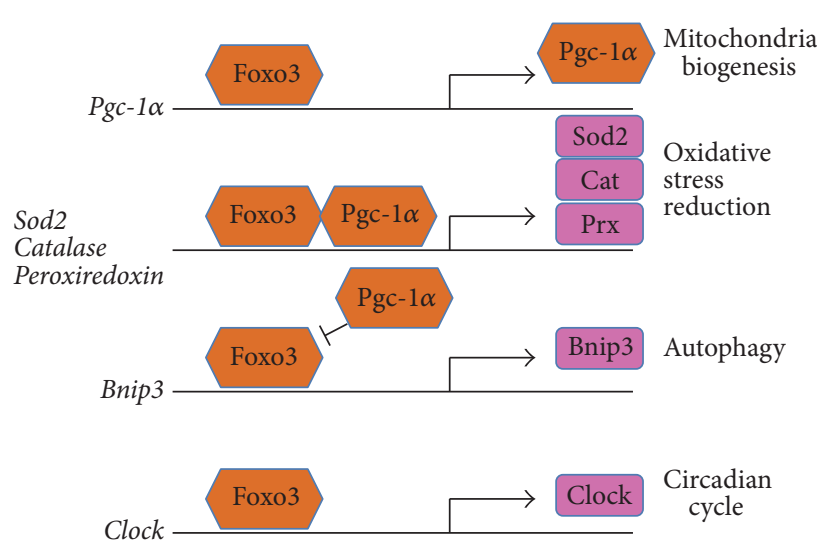

(b)

FIGURE 1: Foxo3's protein network. (a) Negative regulators (blue) of Foxo3 (orange) may act in the cytoplasm (insulin receptor, Akt) or in the nucleus (Cbp). The positive regulators (green) Ampk and sirtuins are activated by energy stress (not depicted), whereas the positive regulator (green) Jnk is activated by other stress pathways (not depicted). Sirtuins and Ampk may act in the cytoplasm or nucleus. (b) Foxo3 targets are discussed in this review. Pgc-1 $\alpha$ (orange) is a transcription factor that coordinates mitochondrial biogenesis; Foxo3 and Pgc- $1 \alpha$ cooperate to induce mitochondrial oxidative stress reduction genes such as Sod2, Cat, and Prx (pink). Foxo3 promotes autophagy by inducing transcription of Bnip3; here Foxo3 is antagonized by Pgc-1 $\alpha$. Lastly, Foxo3 induces Clock expression. All direct interactions shown have been demonstrated in at least one mammalian system (see text).

modification [52]. However, proximity to Cbp also enables Foxo3 acetylation, which lowers its DNA affinity. Thus, Cbp binding first initiates Foxo3-dependent transcriptional activity and then attenuates that activity. However, Foxo3 may be deacetylated by sirtuins, which, as NAD+ dependent enzymes, are activated by energy stress. In summary, Foxo3 transcriptional activity may be activated by multiple stress pathways, and each one can modulate Foxo3 DNA binding affinity to promote the expression of different targets.

Foxo3 expression in the adult mouse cochlea suggests that it acts in sensory cells. Foxo3 protein is detected in the nuclei of spiral ganglion neurons, hair cells, and pillar cells of young adult mice [32]. In contrast, Foxo3 protein was not detected in the stria vascularis [32]. Notably, Foxo3 protein becomes localized to the cytoplasm of spiral ganglion neurons as mice age. Exposure to nondamaging noise levels drives Foxo3 nuclear localization [32]. The latter observation indicates that higher cochlear activity levels promote Foxo3dependent transcription by increasing Foxo3 concentration near DNA.

Foxo3 appears to protect hearing in mice as they age. As young adults, wild-type and Foxo3 knockout (KO) littermates have identical hearing thresholds. However, Foxo3-KO mice develop high-frequency hearing loss by four months of age, whereas their wild-type littermates do not [32]. Surprisingly, inner and outer hair cells, neurons, synapses, and myelin are all present in the high-frequency turn of the Foxo3-KO. Outer hair cell function persists even while hearing thresholds rise, suggesting dysfunction in inner hair cells, auditory synapses, or spiral ganglion neurons. Myo7a localization in inner hair cells is affected, especially near the stereociliary bundles [32]. Synaptic size and positioning are both affected [32]. These data suggest that Foxo3 may regulate an unidentified homeostatic process required for cochlear function.
What might the data from the Foxo3-KO tell us about human hearing loss? First, the fact that Foxo3's location in the cell can change a few hours after nontoxic noise exposure is consistent with the idea that Foxo3 effectors maintain hearing. Second, in the older Foxo3-KO mice, neural components survive yet cease functioning; that is, high-frequency hearing loss develops during adulthood, but hair cells, neurons, and synapses persist. This is striking departure from central neurodegenerative diseases such as Parkinson's, where significant cellular losses precede functional losses. One might wonder if a similar defect impairs human hearing beyond the cellular pathologies discovered in human postmortem samples. Interestingly, around a quarter of postmortem samples from individuals with increased hearing thresholds display no significant cellular losses [11, 27]. Thus, there is a clinical basis for further investigation into mechanisms of cellular dysfunction in the cochlea.

\section{Hearing Loss Can Be a Consequence of Mitochondrial Dysfunction}

Mitochondria power eukaryotic life. The filamentous network of mitochondria is essential for the aerobic generation of ATP via electron transport across membranes, driven by successive redox reactions in the citric acid cycle. Incomplete reduction of the oxygen molecules contained within mitochondrial inner membrane can lead to the generation of superoxides. Cells have evolved multiple layers of enzymatic machinery to reduce superoxides and to detoxify peroxides, their derivative metabolic products. Important mechanisms include the use of glutathione as an electron donor, and mitochondrial enzymes like Sod 2 and members of the peroxiredoxin family (reviewed in [53]). Under stress, these 
protective mechanisms can become overwhelmed, and proteins within mitochondria can become irreversibly damaged through covalent modifications by free radicals. Where this occurs, damaged parts of the mitochondrial network are no longer able to maintain the membrane voltage difference that is the hallmark of the active electron transport chain. Those parts must bud off, or fission, from the network and be targeted for destruction via autophagy [54]. The mitochondrial filamentous network grows through a process called fusion, wherein small mitochondrial fragments unite. Fusion is vital for content mixing and the maintenance of mitochondrial DNA (mtDNA) [53]. This delicate balance of destruction and renewal, of fission and fusion, has important implications for stress responses and the survival of longlived cells.

Some of Foxo3's canonical transcriptional targets are key players in cellular processes that mitigate stress damage to mitochondria (Figure 1(b)). Foxo3 can drive transcription of the master mitochondrial regulator Pgc-1 $\alpha$ [55]. Pgc$1 \alpha$ coordinates new production of mitochondrial proteins from both the nucleus and mitochondrial DNA (mtDNA) [56]. In conjunction with Pgc- $1 \alpha$, Foxo3 directly interacts with the promoters of Sod2, catalase, and peroxiredoxin to drive their expression $[55,57]$. Foxo3-Pgc- $1 \alpha$ interactions have been studied in the brains of Alzheimer's patients [58, 59], rodent models of Alzheimer's [60], human and rodent skeletal muscle $[61,62]$, human and rodent cardiac muscle $[63,64]$, human chondrocytes [65], rodent kidney cells [66], bovine endothelial cells $[55,67]$, rodent pancreas [68], and cells from human patients with mitochondrial disease [69]. Importantly, Foxo3 also promotes the expression of several autophagy proteins, which are implicated in the process that eliminates damaged organelles [70]. Foxo3 drives expression of Bnip3, which is necessary and sufficient to induce Lc3+ autophagosomes under conditions of muscle atrophy [71]. Foxo3-related autophagy studies have been performed in human and rodent skeletal muscle [71-73], human and rodent cardiomyocytes [74-77], human mesenchymal stem cells [78], human chondrocytes [75], rodent kidney cells [79], and rodent liver cells [80]. It may seem paradoxical that Foxo3 is crucial for both mitogenesis and autophagy. In studies of muscle immobilization, it appears that Pgc- $1 \alpha$ and Foxo3 compete as and collaborate: overexpression of Pgc-1 $\alpha$ can suppress Foxo3's ability to promote autophagy [61]. Thus, Foxo3 integrates external stress signals such as excitotoxicity and acts within a network to promote mitochondrial health. This is important because mitochondrial health is strongly implicated in the preservation of hearing.

Mutations that affect mitochondrial function adversely impact hearing as part of a spectrum of neurodegenerative disorders [54]. Mutations in six mitochondrial transfer RNA genes confer either deafness or a susceptibility to aminoglycoside-induced hearing loss [81-86]. Mitochondrial-related genes also underlie such syndromes as Kearns Sayre [87], Mohr-Tranebjaerg [88], and Wolfram [89], each of which may present with hearing loss. A number of nuclear genes that are necessary for mtDNA stability have also been identified, including SUCLA2 [90] and OPA1 [91]. Loss of function in these genes can cause early-onset human hearing loss $[92,93]$. The A1555G mtDNA mutation has been shown to disrupt mitochondrial function through increased methylation of the mitochondrial $12 \mathrm{~S}$ rRNA, a process mediated by the methyltransferase mtTFB1 [94, 95]. It has been recently shown that mice that overexpress mtTFB1 display an increase in 12S RNA methylation and subsequent activation of E2F1dependent apoptosis in spiral ganglion cells, causing hearing loss [96].

Failure of mtDNA integrity is implicated in hearing loss during aging. Mitochondria lack the DNA repair capabilities of the nucleus. As a consequence, mitochondrial DNA accumulates somatic mutations more rapidly than nuclear DNA [97]. Notably, mutations in mitochondrial structural components encoded in mtDNA can accumulate in tissues of the elderly [98]. Such mutations can be selectively amplified from cochlear samples of presbycusis patients but not agematched, normal hearing controls [99]. These age-related mitochondrial mutations are found in spiral ganglion neurons, organ of Corti cells, and the spiral ligament samples when isolated from sections with laser capture [100]. Thus, mitochondrial degeneration associated with aging correlates with hearing loss.

Animal models are used to determine that acute mitochondrial degradation causes hearing loss. When the cochlear mitochondrial respiratory chain is inhibited with 3 nitropropionic acid applied to the round window, permanent hearing loss ensues [101]. The predominant cellular pathology is destruction of fibrocytes in the lateral wall [102]. Mitochondrial oxidizing agents such as cisplatin and paraquat also induce cochlear degeneration $[103,104]$. These data are all consistent with the idea that mitochondrial dysfunction is deleterious for hearing.

Genes that decrease mitochondrial oxidation are also implicated in preventing hearing loss from noise. Sirt3 is a mitochondrial deacetylase that regulates enzymatic activity [105-107]. Sirt3 promotes Sod2 activity [108] and regulates the mitochondrial biogenesis through deacetylation and activation of Pgc-1 $\alpha$ [109]. Mice overexpressing Sirt3 have partial protection from noise damage [110]. In animal models of noise-induced hearing loss, covalent modifications of proteins due to oxidation are increased [111], and treatment with large amounts of dietary antioxidants can partly ameliorate threshold shifts from noise damage [112]. Activation of Sirt3 by administering a precursor to its activator, $\mathrm{NAD}+$, also ameliorates threshold shifts from noise damage in C57BL/6 mice, which is not observed in Sirt3KO mice [110]. Finally, allelic variants in the mitochondrial antioxidants paraoxonase, catalase, and SOD2 are associated with a predisposition to noise-induced hearing loss in human epidemiological studies [113-115]. All three genes decrease mitochondrial oxidative stress. Notably, Sod 2 and catalase are both transcriptionally regulated by Foxo3 (Figure 1(b), [55]).

It is clear that decreasing mitochondrial oxidation is important in preventing hearing loss, as seen in genetic models, aging, acute drug studies, and noise damage. In other systems, Foxo3 governs three key elements for mitochondrial health: mitogenesis, autophagy, and the transcription of mitochondrial oxidative stress reduction proteins. Foxo3's expression in sensory cells, such as hair cells, and not in the 
lateral wall or stria vascularis, suggests that its protective role is restricted to mechanosensory cells rather than the cells that drive the endocochlear potential. Studies of its function in damage paradigms will be integral to understanding its role in this genetic network.

\section{The Circadian Cycle Interacts with Hearing Recovery from Damage}

The diurnal cycle governs the activity of all life. Every eukaryotic cell maintains an independent circadian cycle using two interlocking Clock mechanisms in a manner that is critical for metabolic regulation. In animals, the central nervous system synchronizes these cycles, like a pacemaker, in response to environmental cues [116].

The canonical cellular circadian cycle relies on transcriptional feedback loops to regulate protein expression. The mechanism requires positive effector proteins to drive transcription and negative effector proteins to inhibit the positive effectors. Protein levels for one positive effector, named Clock in mice, remain constant, whereas levels of another positive effector increase through the night. At the start of the day, the positive effectors together drive transcriptional expression of many genes, including the three negative regulators. It is estimated that $8-10 \%$ of transcribed genes receive regulatory input from this mechanism [117]. The negative regulators increase in quantity throughout the day. Prior to the sleep phase, the negative effectors block the positive effectors' function, which are degraded, and then the cycle begins again (reviewed in [116]). It is important to note that the loss of Clock function causes significant abnormalities in circadian behavior [118].

While the transcriptional mechanism of circadian cycle genes was first described decades ago in Drosophila, recently it was found that some metabolic functions maintain circadian cycles independently of transcription or protein synthesis [119]. NADH and NAD+ abundance rise and fall in a 24hour cycle that governs the oxidative status of mitochondrial enzymes like peroxiredoxin [119]. In mouse liver cells, NAD+ levels increase at the start of the Clock cycle and decrease towards the end of the Clock cycle [120]. These oscillations are independent of the nutrient state of the system [120]. Analysis of the mitochondrial proteome shows that its rate-limiting metabolic proteins also vary in levels throughout the day, with their peak production occurring in the early morning [121]. When Clock protein is absent, such oscillations do not occur, significantly impairing mitochondrial function [120].

These data show that the transcriptional Clock machinery interacts with the metabolic Clock mechanism, regulating cellular metabolism, energy use, and oxidative stress response. In mouse liver cells, Foxo3 drives higher levels of Clock expression, promoting circadian cyclical activity [35]. Foxo3 directly binds to elements in the Clock promoter [35]. These findings suggest that Foxo3 regulation of the circadian cycle provides an alternative mechanism for how it maintains hearing. This is interesting because the circadian cycle has a significant impact on the extent of hearing damage from different damage paradigms.
Administration of gentamicin to humans and animals can induce hearing loss $[3,122,123]$. A recent study investigated hearing threshold shifts after daily gentamicin administration. Four groups of circadian-synchronized rats were injected with gentamicin at different times of day, spaced six hours apart from the onset of lights on. Rats receiving injections during daylight have significantly greater hearing loss [124]. It is possible that these differences could arise from circadian regulation of pharmacokinetics, diffusion of drugs to the cochlea, or liver detoxification; however, serum concentrations of gentamicin are similar among the four experimental conditions [124].

A recent report indicates that the circadian cycle also affects the cochlear response to noise, albeit in a different direction [125]. When $\mathrm{CBA} / \mathrm{CaJ}$ mice are exposed to noise, they incur temporary threshold shifts [12], but only if they are exposed during the day [125]. When the same noise exposure is performed at night, the mice incur highfrequency permanent threshold shifts [125]. Given that Bdnf is sufficient to protect neurite innervation in the basal turn of the developing cochlea [126], $B d n f$ levels were investigated after noise exposure. After daytime noise exposure, cochlear $B d n f$ mRNA is upregulated over 30-fold; however, this effect is not observed after noise exposure at night [125]. In vivo treatment with an agonist to the Bdnf receptor prior to noise exposure at night prevents the permanent high-frequency threshold shifts and partially averts synaptic ribbon loss in the basal turn [125]. However, no effect of the agonist was observed when applied prior to a daytime noise exposure [125]. These data are clear evidence that the circadian cycle regulates transcriptional responses to noise exposure, which are key to hearing recovery after injury.

It is interesting to contrast noise damage to gentamicin administration with reference to the circadian cycle: for noise, exposure at night incurs greater damage, whereas, for gentamicin administration, exposure during the daytime does. These opposing papers suggest that the cochlear response to these two damage paradigms is intrinsically different and interacts with different gene pathways. It will be interesting to determine Foxo3's role in the cochlear response to hearing insults.

\section{Concluding Remarks}

The identification of genes involved in early-onset hearing loss has led to a wealth of knowledge about how the cochlea functions [127]. Identification of the genes and processes involved in the maintenance of hearing in adults will similarly lead to an even greater understanding. However, it is likely that multiple pathways interact through positive and negative feedback loops to maintain auditory function [4]. Human genetic diversity, combined with the various experiences of the human condition, may obscure the roles of individual genes and pathways in large scale human studies [4]. I speculate that different cochlear structures, such as the stria vascularis and mechanosensory cells, may rely on distinct gene pathways to promote survival and continued function. Similarly, different damage paradigms likely induce 
distinct responses. Strategies to improve or maintain hearing in humans thus will need to adopt a combinatorial approach, given that human pathology is prominent in multiple cochlear structures. Hence, animal genetic studies, particularly in congenic mouse strains treated with well-defined cochlear insults, may point to new mechanisms that function to maintain hearing. Identification and characterization of such mechanisms could lead to new strategies for therapies to treat hearing loss.

\section{Competing Interests}

The author declares that there are no competing interests regarding the publication of this paper.

\section{Acknowledgments}

The author thanks Dr. Paul Allen, Ms. Holly Beaulac, Ms. Brooke Burgess, Dr. Laurel Carney, Dr. Chris Cederroth, Ms. Felicia Gilels, Dr. Chris Holt, and Dr. Stephen Paquette for comments on the manuscript. The author is supported by R01 DC014261.

\section{References}

[1] NIDCD, Quick Statistics on Hearing Loss Bethesda, MD: National Institute of Health, 2010, https://www.nidcd.nih.gov/ health/statistics/Pages/quick.aspx.

[2] R. Hinchcliffe, "Occupational deafness," Proceedings of the Royal Society of Medicine, vol. 60, pp. 1111-1117, 1967.

[3] S. D. Stephens, "A case of gentamicin accentuated hearing loss," The Journal of Laryngology \& Otology, vol. 82, no. 9, pp. 803808,1968 .

[4] E. Fransen, S. Bonneux, J. J. Corneveaux et al., "Genomewide association analysis demonstrates the highly polygenic character of age-related hearing impairment," European Journal of Human Genetics, vol. 23, no. 1, pp. 110-115, 2015.

[5] G. Van Camp and R. Smith, Hereditary Hearing Loss Homepage, University of Iowa, Iowa City, Iowa, USA, 2015, http:// hereditaryhearingloss.org/.

[6] R. A. Friedman, L. Van Laer, M. J. Huentelman et al., "GRM7 variants confer susceptibility to age-related hearing impairment," Human Molecular Genetics, vol. 18, no. 4, pp. 785-796, 2009.

[7] L. Van Laer, J. R. Huyghe, S. Hannula et al., "A genome-wide association study for age-related hearing impairment in the Saami," European Journal of Human Genetics, vol. 18, no. 6, pp. 685-693, 2010.

[8] G. Girotto, N. Pirastu, R. Sorice et al., "Hearing function and thresholds: a genome-wide association study in European isolated populations identifies new loci and pathways," Journal of Medical Genetics, vol. 48, no. 6, pp. 369-374, 2011.

[9] L. S. Nolan, H. Maier, I. Hermans-Borgmeyer et al., "Estrogenrelated receptor gamma and hearing function: evidence of a role in humans and mice," Neurobiology of Aging, vol. 34, no. 8, pp. 2077.e1-2077.e9, 2013.

[10] D. J. Lim, "Ultrastructural cochlear changes following acoustic hyperstimulation and ototoxicity," Annals of Otology, Rhinology \& Laryngology, vol. 85, no. 6, part 1, pp. 740-751, 1976.
[11] H. F. Schuknecht and M. R. Gacek, "Cochlear pathology in presbycusis," Annals of Otology, Rhinology \& Laryngology, vol. 102, no. 1, part 2, pp. 1-16, 1993.

[12] S. G. Kujawa and M. C. Liberman, "Adding insult to injury: cochlear nerve degeneration after 'temporary' noise-induced hearing loss," Journal of Neuroscience, vol. 29, no. 45, pp. 14077$14085,2009$.

[13] H. W. Lin, A. C. Furman, S. G. Kujawa, and M. C. Liberman, "Primary neural degeneration in the Guinea pig cochlea after reversible noise-induced threshold shift," Journal of the Association for Research in Otolaryngology, vol. 12, no. 5, pp. 605-616, 2011.

[14] S. J. Crowe, S. R. Guild, and L. M. Polvogt, "Observations on the pathology of high-tone deafness," Bulletin of the Johns Hopkins Hospital, vol. 54, no. 5, p. 315, 1934.

[15] R. Pujol and J.-L. Puel, "Excitotoxicity, synaptic repair, and functional recovery in the mammalian cochlea: a review of recent findings," Annals of the New York Academy of Sciences, vol. 884, pp. 249-254, 1999.

[16] R. W. Biagi, "Deafness from dihydrostreptomycin," The British Medical Journal, vol. 2, no. 4732, pp. 651-652, 1951.

[17] L. G. Johnsson, J. E. Hawkins Jr., T. C. Kingsley, F. O. Black, and G. J. Matz, "Aminoglycoside-induced cochlear pathology in man," Acta Oto-Laryngologica, Supplement, vol. 383, pp. 1-19, 1981.

[18] W. C. Stebbins, J. E. Hawkins Jr., L.-G. Johnsson, and D. B. Moody, "Hearing thresholds with outer and inner hair cell loss," American Journal of Otolaryngology-Head and Neck Medicine and Surgery, vol. 1, no. 1, pp. 15-27, 1979.

[19] A. C. Suryadevara, B. A. Schulte, R. A. Schmiedt, and N. B. Slepecky, "Auditory nerve fibers in young and quiet-aged gerbils: morphometric correlations with endocochlear potential," Hearing Research, vol. 161, no. 1-2, pp. 45-53, 2001.

[20] H. Lang, B. A. Schulte, and R. A. Schmiedt, "Effects of chronic furosemide treatment and age on cell division in the adult gerbil inner ear," Journal of the Association for Research in Otolaryngology, vol. 4, no. 2, pp. 164-175, 2003.

[21] R. A. Schmiedt, H. Lang, H.-O. Okamura, and B. A. Schulte, "Effects of furosemide applied chronically to the round window: a model of metabolic presbyacusis," The Journal of Neuroscience, vol. 22, no. 21, pp. 9643-9650, 2002.

[22] E. G. Nelson and R. Hinojosa, "Presbycusis: a human temporal bone study of individuals with downward sloping audiometric patterns of hearing loss and review of the literature," Laryngoscope, vol. 116, supplement 112, no. 9, pp. 1-12, 2006.

[23] J. Otte, H. F. Schunknecht, and A. G. Kerr, "Ganglion cell populations in normal and pathological human cochleae. Implications for cochlear implantation," Laryngoscope, vol. 88, no. 8, pp. 1231-1246, 1978.

[24] F. Suga and J. R. Lindsay, "Histopathological observations of presbycusis," Annals of Otology, Rhinology \& Laryngology, vol. 85, no. 2, part 1, pp. 169-184, 1976.

[25] H. G. Rizk and F. H. Linthicum Jr., "Histopathologic categorization of presbycusis," Otology \& Neurotology, vol. 33, no. 3, pp. e23-e24, 2012.

[26] F. H. Linthicum Jr. and J. N. Fayad, "Spiral ganglion cell loss is unrelated to segmental cochlear sensory system degeneration in humans," Otology \& Neurotology, vol. 30, no. 3, pp. 418-422, 2009.

[27] E. G. Nelson and R. Hinojosa, "Presbycusis: a human temporal bone study of individuals with flat audiometric patterns of 
hearing loss using a new method to quantify stria vascularis volume," Laryngoscope, vol. 113, no. 10, pp. 1672-1686, 2003.

[28] G. A. Gates, D. Mills, B.-H. Nam, R. D’Agostino, and E. W. Rubel, "Effects of age on the distortion product otoacoustic emission growth functions," Hearing Research, vol. 163, no. 1-2, pp. 53-60, 2002.

[29] R. A. Schmiedt, The Physiology of Cochlear Presbycusis. The Aging Auditory System, Springer Science, Berlin, Germany, 2010.

[30] J. R. Engle, S. Tinling, G. H. Recanzone, and J. Snyder, "Agerelated hearing loss in rhesus monkeys is correlated with cochlear histopathologies," PLoS ONE, vol. 8, no. 2, article e55092, 2013.

[31] P. D. Allen and D. A. Eddins, "Presbycusis phenotypes form a heterogeneous continuum when ordered by degree and configuration of hearing loss," Hearing Research, vol. 264, no. 1-2, pp. 10-20, 2010.

[32] F. Gilels, S. T. Paquette, J. Zhang, I. Rahman, and P. M. White, "Mutation of foxo3 causes adult onset auditory neuropathy and alters cochlear synapse architecture in mice," Journal of Neuroscience, vol. 33, no. 47, pp. 18409-18424, 2013.

[33] H. Chen and J. Tang, "The role of mitochondria in age-related hearing loss," Biogerontology, vol. 15, no. 1, pp. 13-19, 2014.

[34] J. Hagenbuchner and M. J. Ausserlechner, "Mitochondria and FOXO3: breath or die," Frontiers in Physiology, vol. 4, article 147, 2013.

[35] I. Chaves, G. T. J. van der Horst, R. Schellevis et al., "InsulinFOXO3 signaling modulates circadian rhythms via regulation of clock transcription," Current Biology, vol. 24, no. 11, pp. 12481255, 2014.

[36] C. Kenyon, J. Chang, E. Gensch, A. Rudner, and R. Tabtiang, "A C. elegans mutant that lives twice as long as wild type," Nature, vol. 366, no. 6454, pp. 461-464, 1993.

[37] R. Martins, G. J. Lithgow, and W. Link, "Long live FOXO: unraveling the role of FOXO proteins in aging and longevity," Aging Cell, vol. 15, no. 2, pp. 196-207, 2015.

[38] F. Flachsbart, A. Caliebe, R. Kleindorp et al., "Association of FOXO3A variation with human longevity confirmed in German centenarians," Proceedings of the National Academy of Sciences of the United States of America, vol. 106, no. 8, pp. 2700-2705, 2009.

[39] C. V. Anselmi, A. Malovini, R. Roncarati et al., "Association of the FOXO3A locus with extreme longevity in a Southern Italian centenarian study," Rejuvenation Research, vol. 12, no. 2, pp. 95103, 2009.

[40] L. Pawlikowska, D. Hu, S. Huntsman et al., "Association of common genetic variation in the insulin/IGF1 signaling pathway with human longevity," Aging Cell, vol. 8, no. 4, pp. 460-472, 2009.

[41] B. J. Willcox, T. A. Donlon, Q. He et al., "FOXO3A genotype is strongly associated with human longevity," Proceedings of the National Academy of Sciences of the United States of America, vol. 105, no. 37, pp. 13987-13992, 2008.

[42] M. Soerensen, S. Dato, K. Christensen et al., "Replication of an association of variation in the FOXO3A gene with human longevity using both case-control and longitudinal data," Aging Cell, vol. 9, no. 6, pp. 1010-1017, 2010.

[43] J. M. Bao, X. L. Song, Y. Q. Hong et al., "Association between FOXO3A gene polymorphisms and human longevity: a metaanalysis," Asian Journal of Andrology, vol. 16, no. 3, pp. 446-452, 2014.
[44] K. Banasik, R. Ribel-Madsen, A. P. Gjesing et al., "The FOXO3A rs2802292 G-allele associates with improved peripheral and hepatic insulin sensitivity and increased skeletal muscleFOXO3A mRNA expression in twins," Journal of Clinical Endocrinology and Metabolism, vol. 96, no. 1, pp. E119-E124, 2011.

[45] A. Brunet, A. Bonni, M. J. Zigmond et al., "Akt promotes cell survival by phosphorylating and inhibiting a forkhead transcription factor," Cell, vol. 96, no. 6, pp. 857-868, 1999.

[46] L. M. Neri, P. Borgatti, S. Capitani, and A. M. Martelli, "The nuclear phosphoinositide 3-kinase/AKT pathway: a new second messenger system," Biochimica et Biophysica Acta-Molecular and Cell Biology of Lipids, vol. 1584, no. 2-3, pp. 73-80, 2002.

[47] S. Ogg, S. Paradis, S. Gottlieb et al., "The fork head transcription factor DAF-16 transduces insulin-like metabolic and longevity signals in C. elegans," Nature, vol. 389, no. 6654, pp. 994-999, 1997.

[48] P. Weisová, D. Dávila, L. P. Tuffy, M. W. Ward, C. G. Concannon, and J. H. M. Prehn, "Role of 5/-adenosine monophosphateactivated protein kinase in cell survival and death responses in neurons," Antioxidants and Redox Signaling, vol. 14, no. 10, pp. 1863-1876, 2011.

[49] E. L. Greer, D. Dowlatshahi, M. R. Banko et al., "An AMPKFOXO pathway mediates longevity induced by a novel method of dietary restriction in C. elegans," Current Biology, vol. 17, no. 19, pp. 1646-1656, 2007.

[50] E. L. Greer, P. R. Oskoui, M. R. Banko et al., "The energy sensor AMP-activated protein kinase directly regulates the mammalian FOXO3 transcription factor," The Journal of Biological Chemistry, vol. 282, no. 41, pp. 30107-30119, 2007.

[51] Z. Li, J. Zhao, I. Tikhanovich et al., "Serine 574 phosphorylation alters transcriptional programming of FOXO3 by selectively enhancing apoptotic gene expression," Cell Death and Differentiation, vol. 23, no. 4, pp. 583-595, 2016.

[52] F. Wang, C. B. Marshall, G.-Y. Li, K. Yamamoto, T. W. Mak, and M. Ikura, "Synergistic interplay between promoter recognition and $\mathrm{CBP} / \mathrm{p} 300$ coactivator recruitment by FOXO3a," ACS Chemical Biology, vol. 4, no. 12, pp. 1017-1027, 2009.

[53] R. A. Gottlieb and D. Bernstein, "Mitochondrial remodeling: rearranging, recycling, and reprogramming," Cell Calcium, vol. 60 , no. 2, pp. 88-101, 2016.

[54] K. Itoh, K. Nakamura, M. Iijima, and H. Sesaki, "Mitochondrial dynamics in neurodegeneration," Trends in Cell Biology, vol. 23, no. 2, pp. 64-71, 2013.

[55] Y. Olmos, I. Valle, S. Borniquel et al., "Mutual dependence of Foxo3a and PGC-1 $\alpha$ in the induction of oxidative stress genes," The Journal of Biological Chemistry, vol. 284, no. 21, pp. 1447614484, 2009.

[56] Z. Wu, P. Puigserver, U. Andersson et al., "Mechanisms controlling mitochondrial biogenesis and respiration through the thermogenic coactivator PGC-1," Cell, vol. 98, no. 1, pp. 115-124, 1999.

[57] G. J. P. L. Kops, T. B. Dansen, P. E. Polderman et al., "Forkhead transcription factor $\mathrm{FOXO} 3$ a protects quiescent cells from oxidative stress," Nature, vol. 419, no. 6904, pp. 316-321, 2002.

[58] W. Qin, V. Haroutunian, P. Katsel et al., "PGC- $1 \alpha$ expression decreases in the alzheimer disease brain as a function of dementia," Archives of Neurology, vol. 66, no. 3, pp. 352-361, 2009.

[59] W. Qin, W. Zhao, L. Ho et al., "Regulation of forkhead transcription factor FoxO3a contributes to calorie restriction-induced 
prevention of Alzheimer's disease-type amyloid neuropathology and spatial memory deterioration," Annals of the New York Academy of Sciences, vol. 1147, pp. 335-347, 2008.

[60] M. Sajan, B. Hansen, R. Ivey III et al., "Brain insulin signaling is increased in insulin-resistant states and decreases in FOXOs and PGC- $1 \alpha$ and increases in $\mathrm{A}_{\beta 1-40 / 42}$ and phospho-tau may abet alzheimer development," Diabetes, vol. 65, no. 7, pp. 18921903, 2016.

[61] C. Kang and L. L. Ji, "PGC-1 $\alpha$ overexpression via local transfection attenuates mitophagy pathway in muscle disuse atrophy," Free Radical Biology and Medicine, vol. 93, pp. 32-40, 2016.

[62] A. R. Konopka, M. D. Douglass, L. A. Kaminsky et al., "Molecular adaptations to aerobic exercise training in skeletal muscle of older women," The Journals of Gerontology, Series A: Biological Sciences and Medical Sciences, vol. 65, no. 11, pp. 1201-1207, 2010.

[63] L. Sun, W.-J. Zang, H. Wang et al., "Acetylcholine promotes ROS detoxification against hypoxia/reoxygenation-induced oxidative stress through FoxO3a/PGC-1 $\alpha$ dependent superoxide dismutase," Cellular Physiology and Biochemistry, vol. 34, no. 5, pp. 1614-1625, 2014.

[64] D. E. Forman, K. M. Daniels, L. P. Cahalin et al., "Analysis of skeletal muscle gene expression patterns and the impact of functional capacity in patients with systolic heart failure," Journal of Cardiac Failure, vol. 20, no. 6, pp. 422-430, 2014.

[65] X. Zhao, F. Petursson, B. Viollet, M. Lotz, R. Terkeltaub, and R. Liu-Bryan, "Peroxisome proliferator-activated receptor $\gamma$ coactivator $1 \alpha$ and FoxO3A mediate chondroprotection by AMP-activated protein kinase," Arthritis and Rheumatology, vol. 66, no. 11, pp. 3073-3082, 2014.

[66] Y. A. Hong, J. H. Lim, M. Y. Kim et al., "Fenofibrate improves renal lipotoxicity through activation of AMPK-PGC- $1 \alpha$ in $d b / d b$ mice," PLoS ONE, vol. 9, no. 5, Article ID e96147, 2014.

[67] Y. Olmos, F. J. Sánchez-Gómez, B. Wild et al., "SirT1 regulation of antioxidant genes is dependent on the formation of a FoxO3a/PGC-1 $\alpha$ complex," Antioxidants \& Redox Signaling, vol. 19, no. 13, pp. 1507-1521, 2013.

[68] Y. R. Chen, Y. L. Lai, S. D. Lin, X. T. Li, Y. C. Fu, and W. C. Xu, "SIRT1 interacts with metabolic transcriptional factors in the pancreas of insulin-resistant and calorie-restricted rats," Molecular Biology Reports, vol. 40, no. 4, pp. 3373-3380, 2013.

[69] S.-B. Wu, Y.-T. Wu, T.-P. Wu, and Y.-H. Wei, "Role of AMPKmediated adaptive responses in human cells with mitochondrial dysfunction to oxidative stress," Biochimica et Biophysica ActaGeneral Subjects, vol. 1840, no. 4, pp. 1331-1344, 2014.

[70] M. Sandri, C. Sandri, A. Gilbert et al., "Foxo transcription factors induce the atrophy-related ubiquitin ligase atrogin-1 and cause skeletal muscle atrophy," Cell, vol. 117, no. 3, pp. 399-412, 2004.

[71] C. Mammucari, G. Milan, V. Romanello et al., "FoxO3 controls autophagy in skeletal muscle in vivo," Cell Metabolism, vol. 6, no. 6, pp. 458-471, 2007.

[72] S. E. Wohlgemuth, H. A. Lees, E. Marzetti et al., "An exploratory analysis of the effects of a weight loss plus exercise program on cellular quality control mechanisms in older overweight women," Rejuvenation Research, vol. 14, no. 3, pp. 315-324, 2011.

[73] M. J. Drummond, O. Addison, L. Brunker et al., "Downregulation of E3 ubiquitin ligases and mitophagy-related genes in skeletal muscle of physically inactive, frail older women: a cross-sectional comparison," Journals of Gerontology-Series A Biological Sciences and Medical Sciences, vol. 69, no. 8, pp. 10401048, 2014.
[74] A. Sengupta, J. D. Molkentin, and K. E. Yutzey, "FoxO transcription factors promote autophagy in cardiomyocytes," The Journal of Biological Chemistry, vol. 284, no. 41, pp. 28319-28331, 2009.

[75] D. K. Kong, S. P. Georgescu, C. Cano et al., "Deficiency of the transcriptional regulator $\mathrm{p} 8$ results in increased autophagy and apoptosis, and causes impaired heart function," Molecular Biology of the Cell, vol. 21, no. 8, pp. 1335-1349, 2010.

[76] A. H. Chaanine, D. Jeong, L. Liang et al., "JNK modulates FOXO3a for the expression of the mitochondrial death and mitophagy marker BNIP3 in pathological hypertrophy and in heart failure," Cell Death and Disease, vol. 3, no. 2, article e265, 2012.

[77] D. J. Cao, N. Jiang, A. Blagg et al., "Mechanical unloading activates $\mathrm{FoxO}_{3}$ to trigger Bnip3-dependent cardiomyocyte atrophy," Journal of the American Heart Association, vol. 2, no. 2, article e000016, 2013.

[78] K. E. van der Vos, P. Eliasson, T. Proikas-Cezanne et al., "Modulation of glutamine metabolism by the PI(3)K-PKBFOXO network regulates autophagy," Nature Cell Biology, vol. 14, no. 8, pp. 829-837, 2012.

[79] S. Kume, T. Uzu, K. Horiike et al., "Calorie restriction enhances cell adaptation to hypoxia through Sirtl-dependent mitochondrial autophagy in mouse aged kidney," The Journal of Clinical Investigation, vol. 120, no. 4, pp. 1043-1055, 2010.

[80] H. Ni, A. Bhakta, S. Wang et al., "Role of hypoxia inducing factor- $1 \beta$ in alcohol-induced autophagy, steatosis and liver injury in mice," PLoS ONE, vol. 9, no. 12, article el15849, 2014.

[81] K. Fu, R. Hartlen, T. Johns, A. Genge, G. Karpati, and E. A. Shoubridge, "A novel heteroplasmic tRNAleu(CUN) mtDNA point mutation in a sporadic patient with mitochondrial encephalomyopathy segregates rapidly in skeletal muscle and suggests an approach to therapy," Human Molecular Genetics, vol. 5, no. 11, pp. 1835-1840, 1996.

[82] M. Crimi, S. Galbiati, M. P. Perini et al., "A mitochondrial tRNAHis gene mutation causing pigmentary retinopathy and neurosensorial deafness," Neurology, vol. 60, no. 7, pp. 12001203, 2003.

[83] N. Gutiérrez Cortés, C. Pertuiset, E. Dumon et al., "Novel mitochondrial DNA mutations responsible for maternally inherited nonsyndromic hearing loss," Human Mutation, vol. 33, no. 4, pp. 681-689, 2012.

[84] I. Nelson, M. G. Hanna, N. Alsanjari, F. Scaravilli, J. A. MorganHughes, and A. E. Harding, "A new mitochondrial DNA mutation associated with progressive dementia and chorea: a clinical, pathological, and molecular genetic study," Annals of Neurology, vol. 37, no. 3, pp. 400-403, 1995.

[85] T. M. Young, E. L. Blakely, H. Swalwell et al., "Mitochondrial transfer RNA(Phe) mutation associated with a progressive neurodegenerative disorder characterized by psychiatric disturbance, dementia, and akinesia-rigidity," Archives of Neurology, vol. 67, no. 11, pp. 1399-1402, 2010.

[86] P. R. Smith, S. C. Bain, P. A. Good et al., "Pigmentary retinal dystrophy and the syndrome of maternally inherited diabetes and deafness caused by the mitochondrial DNA 3243 tRNA(Leu) A to G mutation," Ophthalmology, vol. 106, no. 6, pp. 1101-1108, 1999.

[87] S. Ogasahara, S. Yorifuji, Y. Nishikawa et al., "Improvement of abnormal pyruvate metabolism and cardiac conduction defect with coenzyme $\mathrm{Q}_{10}$ in Kearns-Sayre syndrome," Neurology, vol. 35, no. 3, pp. 372-377, 1985.

[88] C. M. Koehler, D. Leuenberger, S. Merchant, A. Renold, T. Junne, and G. Schatz, "Human deafness dystonia syndrome is 
a mitochondrial disease," Proceedings of the National Academy of Sciences of the United States of America, vol. 96, no. 5, pp. 21411246, 1999.

[89] S. Hofmann, R. Bezold, M. Jaksch, P. Kaufhold, B. ObermaierKusser, and K.-D. Gerbitz, "Analysis of the mitochondrial DNA from patients with Wolfram (DIDMOAD) syndrome," Molecular and Cellular Biochemistry, vol. 174, no. 1-2, pp. 209213, 1997.

[90] O. Elpeleg, C. Miller, E. Hershkovitz et al., "Deficiency of the ADP-forming succinyl-CoA synthase activity is associated with encephalomyopathy and mitochondrial DNA depletion," The American Journal of Human Genetics, vol. 76, no. 6, pp. 10811086, 2005.

[91] M. Herlan, F. Vogel, C. Bornhövd, W. Neupert, and A. S. Reichert, "Processing of Mgml by the rhomboid-type protease Pcpl is required for maintenance of mitochondrial morphology and of mitochondrial DNA," Journal of Biological Chemistry, vol. 278, no. 30, pp. 27781-27788, 2003.

[92] R. Carrozzo, C. Dionisi-Vici, U. Steuerwald et al., "SUCLA2 mutations are associated with mild methylmalonic aciduria, Leigh-like encephalomyopathy, dystonia and deafness," Brain, vol. 130, no. 3, pp. 862-874, 2007.

[93] A. Roubertie, N. Leboucq, M. C. Picot et al., "Neuroradiological findings expand the phenotype of OPA1-related mitochondrial dysfunction," Journal of the Neurological Sciences, vol. 349, no. 1-2, pp. 154-160, 2015.

[94] V. McCulloch, B. L. Seidel-Rogol, and G. S. Shadel, "A human mitochondrial transcription factor is related to RNA adenine methyltransferases and binds S-adenosylmethionine," Molecular and Cellular Biology, vol. 22, no. 4, pp. 1116-1125, 2002.

[95] B. L. Seidel-Rogol, V. McCulloch, and G. S. Shadel, "Human mitochondrial transcription factor B1 methylates ribosomal RNA at a conserved stem-loop," Nature Genetics, vol. 33, no. 1, pp. 23-24, 2003.

[96] N. Raimundo, L. Song, T. E. Shutt et al., "Mitochondrial stress engages E2F1 apoptotic signaling to cause deafness," Cell, vol. 148, no. 4, pp. 716-726, 2012.

[97] H. C. Lee and Y. H. Wei, "Mitochondria and aging," in Advances in Mitochondrial Medicine, vol. 942 of Advances in Experimental Medicine and Biology, pp. 311-327, Springer, Berlin, Germany, 2012.

[98] G. A. Cortopassi and N. Arnheim, "Detection of a specific mitochondrial DNA deletion in tissues of older humans," Nucleic Acids Research, vol. 18, no. 23, pp. 6927-6933, 1990.

[99] A. Markaryan, E. G. Nelson, and R. Hinojosa, "Quantification of the mitochondrial DNA common deletion in presbycusis," Laryngoscope, vol. 119, no. 6, pp. 1184-1189, 2009.

[100] A. Markaryan, E. G. Nelson, and R. Hinojosa, "Detection of mitochondrial DNA deletions in the cochlea and its structural elements from archival human temporal bone tissue," Mutation Research/Fundamental and Molecular Mechanisms of Mutagenesis, vol. 640, no. 1-2, pp. 38-45, 2008.

[101] N. Hoya, Y. Okamoto, K. Kamiya, M. Fujii, and T. Matsunaga, "A novel animal model of acute cochlear mitochondrial dysfunction," NeuroReport, vol. 15, no. 10, pp. 1597-1600, 2004.

[102] Y. Okamoto, N. Hoya, K. Kamiya, M. Fujii, K. Ogawa, and T. Matsunaga, "Permanent threshold shift caused by acute cochlear mitochondrial dysfunction is primarily mediated by degeneration of the lateral wall of the cochlea," Audiology \& Neurotology, vol. 10, no. 4, pp. 220-233, 2005.
[103] P. Evans and B. Halliwell, "Free radicals and hearing: cause, consequence, and criteria," Annals of the New York Academy of Sciences, vol. 884, pp. 19-40, 1999.

[104] E. C. Bielefeld, B. H. Hu, K. C. Harris, and D. Henderson, "Damage and threshold shift resulting from cochlear exposure to paraquat-generated superoxide," Hearing Research, vol. 207, no. 1-2, pp. 35-42, 2005.

[105] M. B. Scher, A. Vaquero, and D. Reinberg, "SirT3 is a nuclear $\mathrm{NAD}+$-dependent histone deacetylase that translocates to the mitochondria upon cellular stress," Genes \& Development, vol. 21, no. 8, pp. 920-928, 2007.

[106] D. B. Lombard, F. W. Alt, H.-L. Cheng et al., "Mammalian Sir2 homolog SIRT3 regulates global mitochondrial lysine acetylation," Molecular and Cellular Biology, vol. 27, no. 24, pp. 8807-8814, 2007.

[107] M. J. Rardin, J. C. Newman, J. M. Held et al., "Label-free quantitative proteomics of the lysine acetylome in mitochondria identifies substrates of SIRT3 in metabolic pathways," Proceedings of the National Academy of Sciences of the United States of America, vol. 110, no. 16, pp. 6601-6606, 2013.

[108] H.-S. Kim, K. Patel, K. Muldoon-Jacobs et al., "SIRT3 is a mitochondria-localized tumor suppressor required for maintenance of mitochondrial integrity and metabolism during stress," Cancer Cell, vol. 17, no. 1, pp. 41-52, 2010.

[109] K. Aquilano, P. Vigilanza, S. Baldelli, B. Pagliei, G. Rotilio, and M. R. Ciriolo, "Peroxisome proliferator-activated receptor $\gamma$ co-activator $1 \alpha(\mathrm{PGC}-1 \alpha)$ and sirtuin 1 (SIRT1) reside in mitochondria: possible direct function in mitochondrial biogenesis," The Journal of Biological Chemistry, vol. 285, no. 28, pp. 21590-21599, 2010.

[110] K. D. Brown, S. Maqsood, J.-Y. Huang et al., "Activation of SIRT3 by the $\mathrm{NAD}^{+}$precursor nicotinamide riboside protects from noise-induced hearing loss," Cell Metabolism, vol. 20, no. 6, pp. 1059-1068, 2014

[111] J. Samson, A. Wiktorek-Smagur, P. Politanski et al., "Noiseinduced time-dependent changes in oxidative stress in the mouse cochlea and attenuation by D-methionine," Neuroscience, vol. 152, no. 1, pp. 146-150, 2008.

[112] R. D. Kopke, P. A. Weisskopf, J. L. Boone et al., "Reduction of noise-induced hearing loss using L-NAC and salicylate in the chinchilla," Hearing Research, vol. 149, no. 1-2, pp. 138-146, 2000.

[113] Y.-M. Liu, X.-D. Li, X. Guo et al., "SOD2 V16A SNP in the mitochondrial targeting sequence is associated with noise induced hearing loss in Chinese workers," Disease Markers, vol. 28, no. 3, pp. 137-147, 2010.

[114] A. Konings, L. Van Laer, M. Pawelczyk et al., "Association between variations in CAT and noise-induced hearing loss in two independent noise-exposed populations," Human Molecular Genetics, vol. 16, no. 15, pp. 1872-1883, 2007.

[115] G. Fortunato, E. Marciano, F. Zarrilli et al., "Paraoxonase and superoxide dismutase gene polymorphisms and noise-induced hearing loss," Clinical Chemistry, vol. 50, no. 11, pp. 2012-2018, 2004.

[116] S. Ray and A. B. Reddy, "Cross-talk between circadian clocks, sleep-wake cycles, and metabolic networks: dispelling the darkness," BioEssays, vol. 38, no. 4, pp. 394-405, 2016.

[117] K.-F. Storch, O. Lipan, I. Leykin et al., "Extensive and divergent circadian gene expression in liver and heart," Nature, vol. 417, no. 6884, pp. 78-83, 2002.

[118] D. P. King, M. H. Vitaterna, A.-M. Chang et al., "The mouse Clock mutation behaves as antimorph and maps within the 
W(19H) deletion, distal of Kit," Genetics, vol. 146, no. 3, pp. 1049-1060, 1997.

[119] J. S. O’Neill and A. B. Reddy, “Circadian clocks in human red blood cells," Nature, vol. 469, no. 7331, pp. 498-503, 2011.

[120] C. B. Peek, A. H. Affinati, K. M. Ramsey et al., "Circadian clock $\mathrm{NAD}^{+}$cycle drives mitochondrial oxidative metabolism in mice," Science, vol. 342, no. 6158, Article ID 1243417, 2013.

[121] A. Neufeld-Cohen, M. S. Robles, R. Aviram et al., "Circadian control of oscillations in mitochondrial rate-limiting enzymes and nutrient utilization by PERIOD proteins," Proceedings of the National Academy of Sciences, vol. 113, no. 12, pp. E1673-E1682, 2016.

[122] A. Forge, "Outer hair cell loss and supporting cell expansion following chronic gentamicin treatment," Hearing Research, vol. 19, no. 2, pp. 171-182, 1985.

[123] B. Kotecha and G. P. Richardson, "Ototoxicity in vitro: effects of neomycin, gentamicin, dihydrostreptomycin, amikacin, spectinomycin, neamine, spermine and poly-l-lysine," Hearing Research, vol. 73, no. 2, pp. 173-184, 1994.

[124] W. Mckinney, A. Yonovitz, and M. H. Smolensky, "Circadian variation of gentamicin toxicity in rats," Laryngoscope, vol. 125, no. 7, pp. E252-E256, 2015.

[125] I. Meltser, C. R. Cederroth, V. Basinou, S. Savelyev, G. S. Lundkvist, and B. Canlon, "TrkB-mediated protection against circadian sensitivity to noise trauma in the murine cochlea," Current Biology, vol. 24, no. 6, pp. 658-663, 2014.

[126] I. Fariñas, K. R. Jones, L. Tessarollo et al., "Spatial shaping of cochlear innervation by temporally regulated neurotrophin expression," The Journal of Neuroscience, vol. 21, no. 16, pp. 61706180, 2001.

[127] A. A. Dror and K. B. Avraham, "Hearing impairment: a panoply of genes and functions," Neuron, vol. 68, no. 2, pp. 293-308, 2010. 


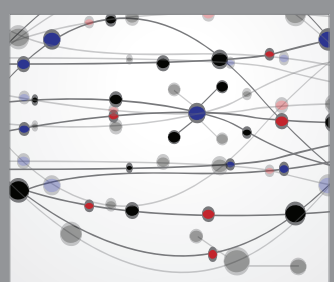

The Scientific World Journal
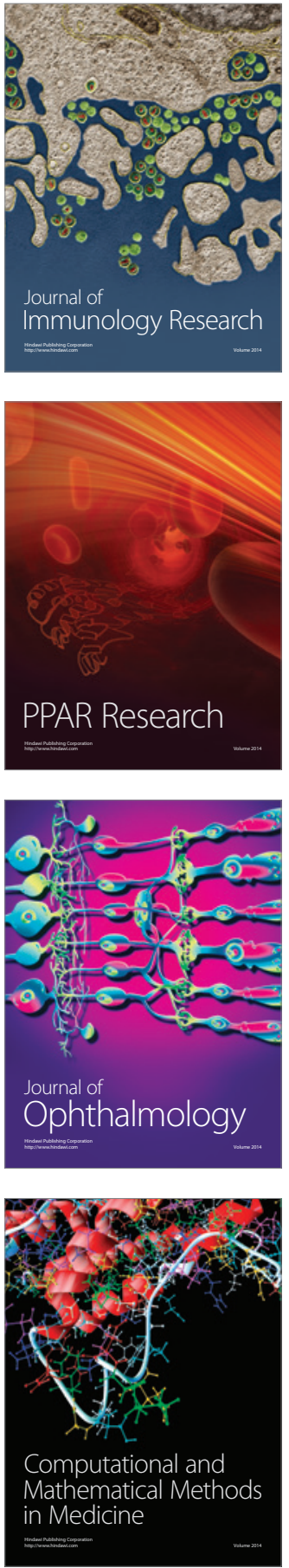

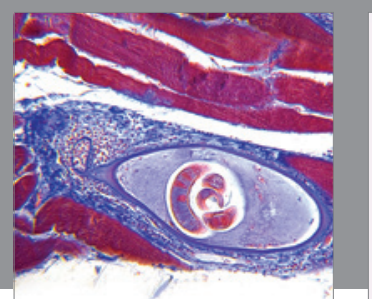

Gastroenterology Research and Practice

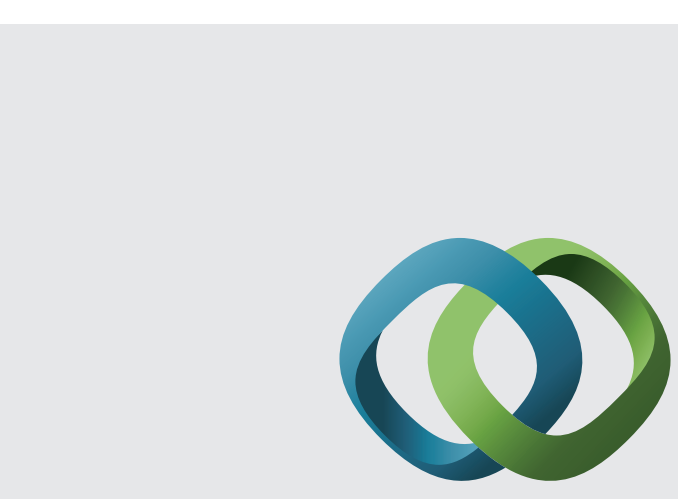

\section{Hindawi}

Submit your manuscripts at

http://www.hindawi.com
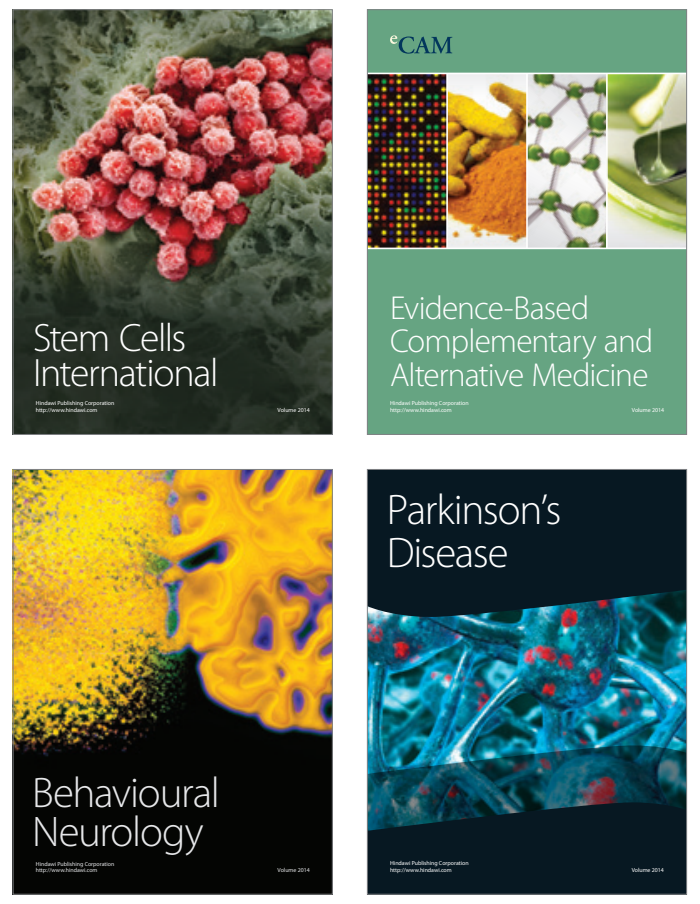
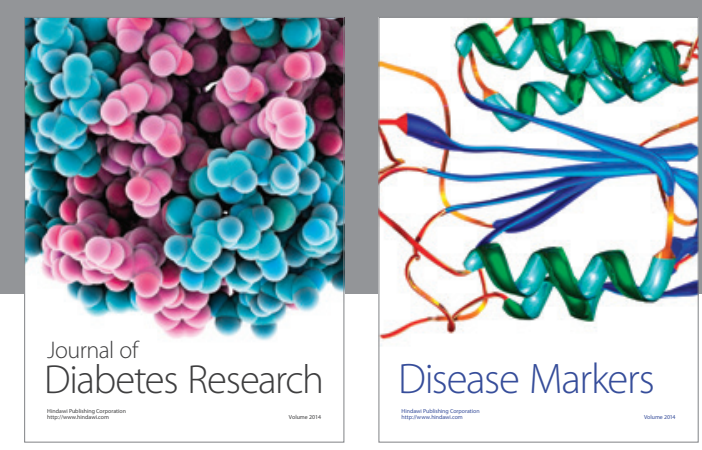

Disease Markers
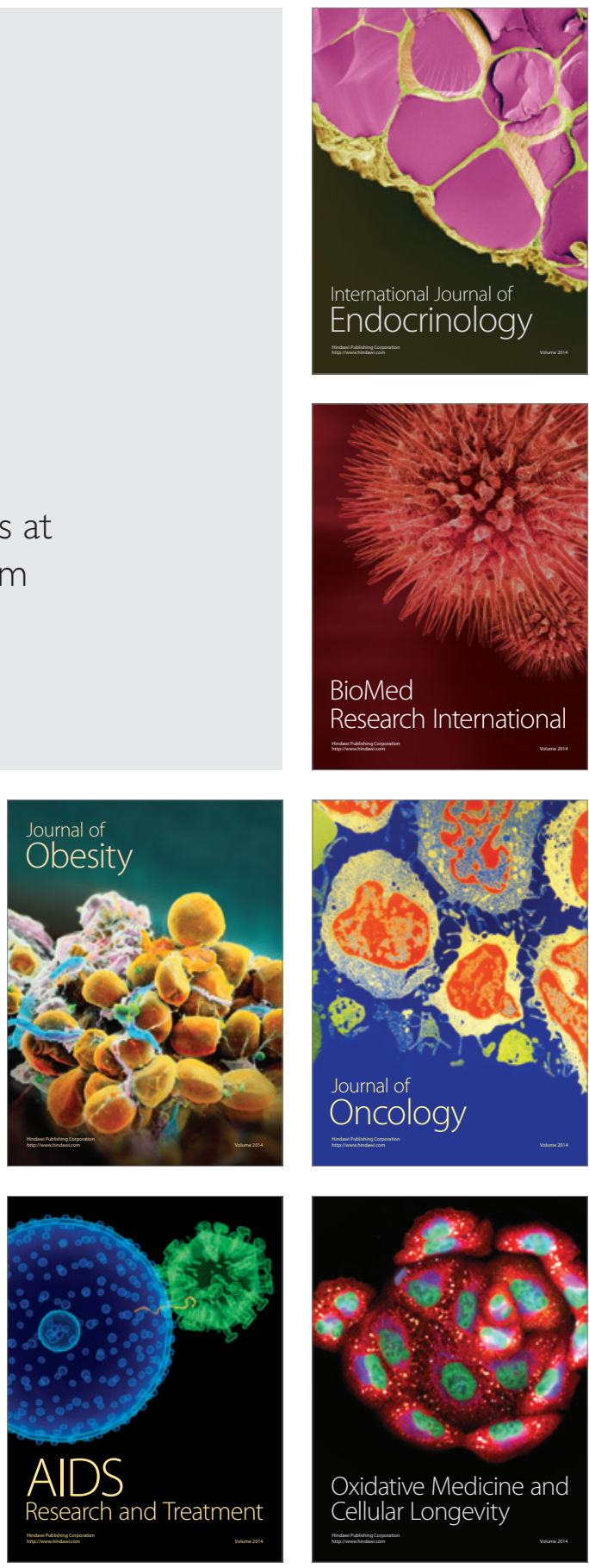